\title{
Cultural intelligence among Indonesian students: Role of international experiences and their impact on the development of social network and adaptive performance
}

\author{
Lieli Suharti ${ }^{1, *}$ Ariawan Pramono ${ }^{2}$ \\ ${ }^{1,2}$ Faculty of Economics and Business, Satya Wacana Christian University, Indonesia
}

Keywords:

Cultural intelligence

International exposure

Adaptive performance

Development social network

Received: 9 April 2016

Accepted: 25 April 2016

Published: 21 June 2016

\begin{abstract}
This research aims to examine the factors that influence cultural intelligence and its impact on social networks development and adaptive performance among Indonesian students. The formulation of research problems are as follows: 1) Is vacation abroad influence the cultural intelligence of Indonesian students?; 2) Is education abroad influence the cultural intelligence of Indonesian students?; 3) Is social network development and adaptive performance influenced by the cultural intelligence of Indonesian students? This study was explanatory research that explained the correlation between variables by using a quantitative approach. By using the purposive sampling technique, this study involves 133 students from Indonesia who had experiences abroad. The analysis technique used in this study was Structural Equation Model (SEM). The results showed that international exposure does not affect cultural intelligence. On the other hand, this research proves that cultural intelligence influences social network development and adaptive performance.
\end{abstract}

(C) 2016 The Author(s). Published by TAF Publishing.

\section{INTRODUCTION}

Rapid technology and information development at present gives a great impact to the various sectors. In a book written by Friedman (2005) it is stated that the earth has no limits anymore since it is easily accessible by anyone and change the way of an industry in running its business. The advance of such globalization makes diverse workforce to be apperared in organizations which have a variety of different cultures and customs. According to Kanten (2014) the company must be able to recognize and regulate the cultural differences that exist so that the workers can work harmoniously and effectively.

\footnotetext{
*Corresponding author: Lieli Suharti

E-mail: lieli.suharti@staff.uksw.edu
} 
The problem that often occurs when a worker faces new working environment is unprepared in experiencing cultural shock. As said by Shieh (2013) the cultural shock is the current state of someone who is already accustomed to living in a familiar environment and then move to a new environment for work, school or vacation. Cultural shock is influenced by the nature of the individual, demographic factors and the support of the organization where a person is working or studying. The height of Cultural Intelligence will help someone in dealing with situations of culture shock in a multi cultural which can create stress and frustration since someone who has a high Cultural Intelligence will easily adapt to communicate, behave and build friendships more to support him or her in the new environment.

It is now considered that cultural difference is important to be studied. Some researchers found Cultural Intelligence (CI) as one measuring tool in seeing someone's personality. Cultural Intelligence (CI) is the ability to adapt to the environment around which is different that the culture where the person lived before (Rose and Naresh, 2008). As said by Livermore (2011) a person who has a high Cultural Intelligence will be able to determine the strategy and the attitude in facing foreign culture and behavior. The level of Cultural Intelligence of someone can be measured from the Cultural Intelligence component which consists of meta-cognitive, cognitive, behavioral and motivational components (Ang et al., 2005).

One of the variables that have impact on Cultural Intelligence is international experience that is a way to go abroad for a vacation or to attend school (Ng et al., 2012). Someone who has ever traveled abroad will has an ability interact with new cultures. These experiences will enrich experience and knowledge about a new culture that will improve the Cultural Intelligence.

According to Ang et al. (2011) Cultural Intelligence has an impact on the development of a person's social network. Cultural Intelligence will affect a person's behavior in interacting with others. Someone who has a high Cultural Intelligence will be easy to interact with other cultures so that it will also make other people comfortable when they are around him or her. It makes a person to have a lot of friends who provide support in the world of work.

In addition, Cultural Intelligence also affects a person in adapting to the new environment (Soldatova and Marina, 2013). This is shown by the more creative and innovative work in person with high Cultural Intelligence compared with those with low Cultural Intelligence. Furthermore, a person is said to be able to adapt from his or her bravery in leading a new group.

The implementation of ASEAN Economic Community (AEC) will be conducted in December 2015. AEC aims to boost economic growth in the region by lowering the barrier limits in the exchange of goods, services, workers who have special skills such as nurses, doctors, teachers, and others, and also provide an opportunity to invest efforts in other ASEAN countries (Pangestu, 2009). With the entry of other ASEAN countries to Indonesia, Indonesian society is also expected to fill the void of labor in other ASEAN countries. For that we need a good adaptability to be able to work together with others, especially students as prospective employees.

Recently, Indonesia still send a lot of unskilled labor to work abroad compared to Philippines (Primasanto in Fernandes and dan Andadari 2012). The level of manpower development index or Human Development Index (HDI) 
in Indonesia has increased from year to year but still below other ASEAN countries. Currently, Indonesia is ranked 108, lower that other ASEAN countries such as Malaysia (62), Singapore (9), Thailand (89), Brunei Darussalam (30) (UNDP, 2013). Education can raise the HDI of a country one of which the skill education obtained from the university. It shows that the quality of students plays an important role in the development of a country both in economic and social sectors.

Problems raised in this study are the factors that influence the Cultural Intelligence, and its impact on social networks development and adaptive performance among Indonesian students. In more detail, the formulation of research problems are as follows: 1) Is vacation abroad influence the CI of Indonesian students?; 2) Is education abroad influence the CI of Indonesian students?; 3) Is social network development and adaptive performance influenced by the CI of Indonesian students?.

\section{LITERATURE REVIEW AND HYPOTHESIS FORMULATION Education Abroad and CI}

Cultural Intelligence (CI) is a person's ability to interact with others effectively when entering the environment with different cultures (Van Dyne et al., 2008). CI may explain why a person can survive in the new environment and culture while others are difficult to adapt. Based on Early and Soon (2003) and Ang et al. (2011), CI has four components, namely Metacognitive, Cognitive, Behavioral, and Motivational.

Cognitive CI is one's knowledge about the norms, manners, behavior, rules and social aspects of a culture obtained from formal education and personal experience (Rockstuhl et al., 2011). Meta-Cognitive CI can be interpreted as one's strategy to be able to adapt with the new environment. In contrast to cognitive $\mathrm{CI}$, meta-cognitive $\mathrm{CI}$ tends to show how to find a gap to the minds of others and be able to commune with the current situation (Van Dyne et al., 2010).

Furthermore, according to Van Dyne et al. (2012) motivational CI is the mental attitude to encourage someone to pay attention and learn about the cultural differences that the person will be or are being experienced. High and low $\mathrm{CI}$ are influenced by Intrinsic Interest, Extrinsic Interest and SelfConfidence (Van Dyne et al., 2012; Ng et al., 2012).

Kitsantas and Meyers (2001) defined education aboard as all programs that aimed to educate that was performed outside the geographical lines of original country. Taking education abroad aims to raise awareness of the interdependence among countries, increase the value of difference, and gain other important information about other countries. It is expected that after taking education abroad, students can compete in the global market, gain an increase in foreign language and have a broad network.

Education abroad will affect the CI because according Crowne (2008) study abroad will give an opportunity to a person to interact with others from different cultures. By getting along with people in different culture, someone must adjust to new cultural habits in order to avoid discrimination or other negative treatment as a result of an error in interacting with new environments (Ang et al., 2011). Therefore, someone who get education abroad has a potential to improve his or her CI. Thus the following hypothesis can be formulated: 
H1: Education abroad will have a positive impact on CI

\section{Vacation Abroad and CI}

Takeuchi et al. (2005) defined vacation abroad as an activity that had no connection with the work performed abroad. Vacation abroad is aimed to give a rest to the mind, so that the mind can be cleared when it is used in working again. For the company, usually vacation abroad is also used as a bonus to employees who have achievements to motivate others in working to get the same bonus to those employees.

In a study conducted by Tarique and Takeuchi (2008) in Ang, Van Dyne, and Tan (2011) it was found that vacation or holiday affected the height of CI. The number of countries that had been visited became the deciding factor for high and low CI because by visiting many different countries someone would had more interaction with strangers. A lot of interaction with a diverse culture will enhance knowledge and provide a diverse experience. Based on the above rationale, the following hypothesis can be formulated:

H2: Vacation Abroad will have a positive impact on CI

\section{CI and Adaptive Performance}

Adaptive performance is defined by Shoss et al. (2012) as a person's behavior in accepting something new change in a new environment. Adaptive performance is a benefit for the company or environment in which a person lives because good adaption may creates harmony among individuals in the neighborhood. Someone who has adaptive performance can be seen from his or her willingness to accept higher responsibility, for example, be a leader in group work, can finish the job in a creative albeit or in a new environment and want to interact with the new environment.

According to $\mathrm{Ng}$ and Christopher (2006), CI has an influence on adaptive performance that is the individual's ability to adapt to his or her environment. Someone who has a high CI will be easy to adjust his behavior to the new environment. Van der Zee et al. in Leung et al. (2014) found that students who had high CI could more easily adapt to the working environment with cultural diversity. From the results of research conducted by Harrison and Brower (2011) it was also revealed that students who were able to adapt to the environment had a high level of CI. Based on the logic of thinking above, the following hypotheses can be formulated:

H3: CI will have a positive impact on Adaptive Performance

\section{CI and Social Network}

According to De Lange et al. (2004), a structured relationship and have reciprocal relationships between individuals is referred to as social network. An individual has a social relationship network both formally and informally. The level of a person's ability to develop a social network is known as the capability of social networks development, which can be measured by the number of friends and local diversity of the friends.

According to Ng et al. (2012) and Ang et al. (2011), CI is one of a person's abilities which can affect the ability of many social relationships outside the geographic boundaries with different cultures and ethnicities. Someone who has a high CI will have many friends who will provide support and advice, since 
the people around him or her are comfortable to interact with the mutual understanding of cultural differences that exist. Therefore, the following hypotheses can be formulated:

H4: CI will have a positive impact on Social Network Development

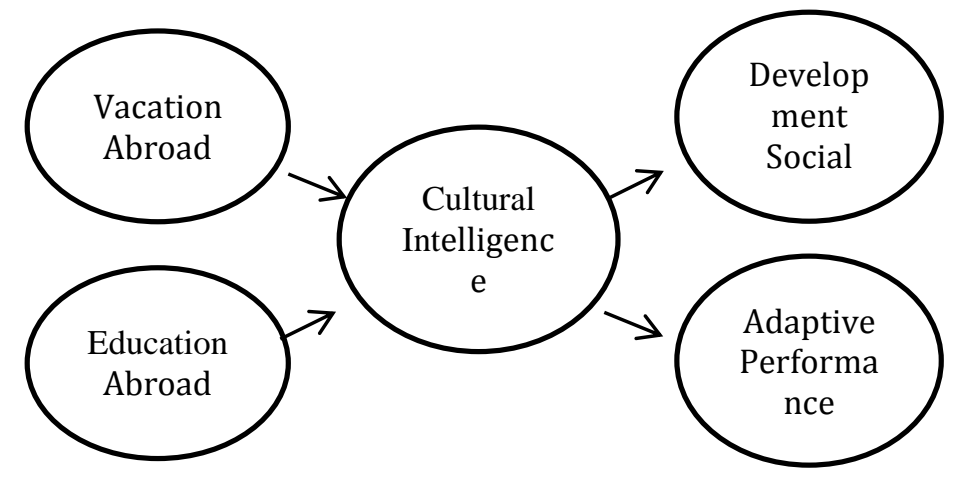

FIGURE 1. Proposed research model

RESEARCH METHODS

This study was an explanatory research that explained the correlation between variables that would be examined each other and would be examined by using a quantitative approach.

The populations in this study were students from Indonesia who had experiences abroad, both the educational experience abroad and also experience of traveling abroad. Because the number of the population studied is not certainly known, the sampling in this study used purposive sampling technique.

The number of samples examined here were in accordance with that recommended by Hair and Black (2000) with the total number of 140 respondents, but those could be processed were only 133 respondents where the number of study samples for hypotheses test used Structural Equation Model (SEM) ranged between 100-200 samples. The questionnaires distribution was conducted to the respondents of Indonesian students who were abroad, were collected online by contacting any Indonesian Students Association committee abroad (Malaysia, Thailand, India).

The measurement of Cultural Intelligence variable consisted of cognitive CI, metacognitive $\mathrm{CI}$, motivational $\mathrm{CI}$, behavioral $\mathrm{CI}$ by adopting the Ang et al. (2011). Vacation abroad variable was measured by question items by using a $\mathrm{Ng}$ et al. (2012). Education abroad used a Crowne scale (2008), Adaptive Performance and Development of Social Network variables adopted the scale developed by Ng et al. (2012).

Every answer that was spread from online questionnaires was administered by using google drive. The entered data were processed directly into the form of xls data in Microsoft Excel program. Answers and responses from the respondents were measured by using a Likert scale with responses from 1 (strongly disagree) to 5 (strongly agree).

The analysis technique used in this study was Structural Equation Model (SEM). The first analysis process conducted were validity and reliability tests of 
the latent constructs by using confirmatory factor analysis (CFA) to determine whether the indicator variables could actually represented the latent variables or not. After over all fit model process led to the good conclusion, then the next step was to see whether there was a significant correlation between the independent variables (exogenous) with dependent variables (endogenous) or not. The hypothesis was formulated based on the correlation of the structural model depiction.

\section{FINDINGS AND DISCUSSION}

To determine the tendency of respondents' answers in the questionnaires then the descriptive statistics to see the average value (the mean) will be presented following. The scores were grouped into intervals of the study variables.

TABLE 1. Descriptive statistics of CI variable

\begin{tabular}{clcc}
\hline \hline No. & Description & Mean & Notes \\
\hline 1 & Cognitive CI & 3.75 & High \\
\hline 2 & Metacognitive CI & 4.09 & High \\
\hline 3 & Motivational CI & 3.65 & High \\
\hline 4 & Behavioral CI & 3.75 & High \\
\hline \multicolumn{2}{l}{ Cultural Intelligence } & 3.81 & High \\
\hline \hline
\end{tabular}

From the Table 1 above it could be seen that the highest value was metacognitive CI. Metacognitive CI owned by the respondent wsa especially when the respondents interacted in another culture to prepare the right words in communication. The average value of the overall Motivational CI was also likely to be high with a value of 3.65. From the analysis of the study data it could be concluded that the respondents had a high Motivational CI especially when the respondents could reduce or controlled the stress experienced when interacting with a new culture.

The average value of Behavioral CI was likely to be high with a value of 3.75. The adjustment of foreign grammar while communicating with other cultures by the respondents could be performed well. It referred to the the average value acquisition of the respondents above.

TABLE 2. Descriptive statistics of vacation abroad variable

\begin{tabular}{cccc}
\hline No. & Description & Mean & Notes \\
\hline 1 & $\begin{array}{c}\text { Vacation to some other countries in } \\
\text { a long period }\end{array}$ & 2.64 & Moderate \\
\hline 2 & $\begin{array}{l}\text { Vacation to some other countries } \\
\text { Intensity of vacation to another } \\
\text { country in the near future }\end{array}$ & 2.94 & Moderate \\
\hline 3 & Low & \\
\hline \hline
\end{tabular}

Source: Primary Data Analysis, 2015. 
The above data showed that students did not have a long experience in holidays abroad. International Exposure (IE) of 18 showed that the students were just been on a vacation to a few countries with a value of 2.94. The intensity of a vacation in the near future to other countries of very few respondents was indicated the value of 1.83 which was categorized as low.

TABLE 3. Descriptive statistics of education abroad variable

\begin{tabular}{cccc}
\hline \hline No & Description & Mean & Notes \\
\hline 1 & The level of education in other & 3.11 & Moderate \\
countries & $\begin{array}{c}\text { Studied in another country in the } \\
\text { long period }\end{array}$ & 3.22 & Moderate \\
\hline 2 & Studied in several countries & 1.32 & Very Low \\
\hline 3
\end{tabular}

Source: Primary Data Analysis, 2015.

By looking at the acquisition value of each Education abroad variable above, it could be explained that education in the long term, got the highest value with a value of 3.22. From these values it could be said that the respondents had little international experience in the terms of going abroad to study. The data showed that a few number Indonesian students studied in several countries.

TABLE 4. Descriptive statistics of adaptive performance variable

\begin{tabular}{clcc}
\hline \hline No & \multicolumn{1}{c}{ Description } & Mean & Notes \\
\hline 1 & $\begin{array}{l}\text { Want to lead a group consisting of } \\
\text { people from different cultures }\end{array}$ & 3.33 & Moderate \\
\hline 2 & $\begin{array}{l}\text { Can complete the task creatively } \\
\text { although in a new cultural } \\
\text { environment }\end{array}$ & 3.65 & High \\
\hline 3 & $\begin{array}{l}\text { Want to interact with the } \\
\text { unknown/uncertain environment }\end{array}$ & High \\
\hline
\end{tabular}

International Exposure (IE) of 24 in Table 4 above got the highest average value of 3.67 which showed that the respondents could complete the task creatively although in a new cultural environment with a value of 3.65 . It can be said that the respondents could adapt to a new culture when it was viewed from a performance held mainly in the terms of the completion of the task obtained. Overall average value of Adaptive Peformance variable was also likely to be high with a value of 3.52 .

TABLE 5. Descriptive statistics of social network development variable

\begin{tabular}{clcc}
\hline \hline No & Description & Mean & Notes \\
\hline 1 & $\begin{array}{l}\text { Have a lot of friends from other } \\
\text { cultures }\end{array}$ & 3.95 & High \\
\hline 2 & $\begin{array}{l}\text { Have a lot of friends with a diverse } \\
\text { culture }\end{array}$ & 3.98 & High \\
\hline 3 & $\begin{array}{l}\text { Still in touch with friends who are } \\
\text { known from different countries or }\end{array}$ & 3.92 & High \\
\hline \hline
\end{tabular}




\begin{tabular}{ccc}
\hline \hline \multicolumn{2}{c}{ cultures } & \\
\hline Average & 3.95 & High \\
\hline \hline
\end{tabular}

Table 5 explained that the respondents had many friends with a diverse culture as shown by the value of 3.98 which was the highest value and the entire average value of Social Network Development tent to be high with a value of 3.95 .

\section{STUDY RESULTS}

At this stage, the determination of the initial model and further research is performed and then also the model identification. From the convergent and discriminant validity tests, some indicators did not have a significant correlation with the latent, so the modification was necessary, that was by eliminating the Vacation Abroad variable because the indicator did not exist which may explain this latent.

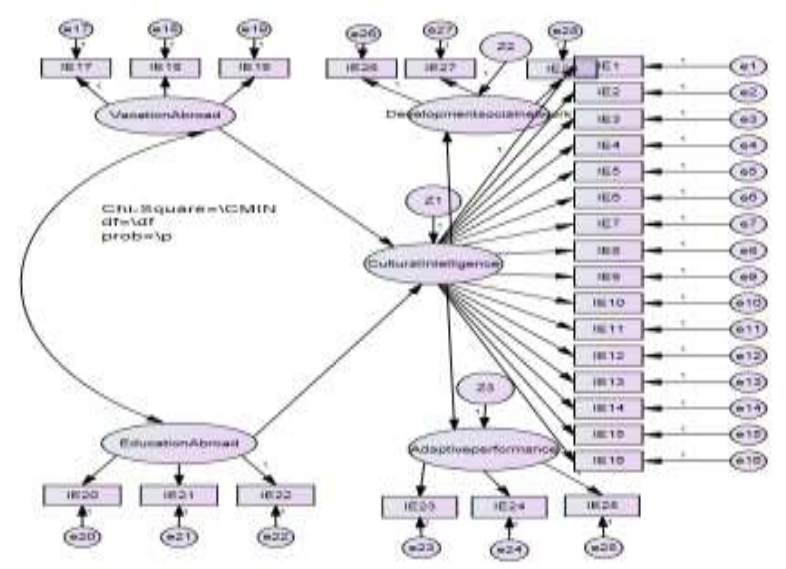

FIGURE 2. Initial model

Besides, both latent variables did not meet the assumption of reliability. So we can say that there were no indicators that could explain the exogenous latent variables of Vacation Abroad and Education Abroad. Thus, in the second modeling these two variables would be eliminated.

In the stage of Endogenous CFA II, the modification was performed by eliminating some of the indicators that had weak correlation with the latent, in this case IE2, IE3, IE4, IE5, IE14, and IE15. In the stage of Endogenous CFA III, although it had not yet meet the assumption of reliability but from the table above the criteria had shown good results. So model modification of endogenous CFA was no longer needed. The next stage was making whole structural model based on the CFA that had been made. Here are the specifications of the final model after the modification. 


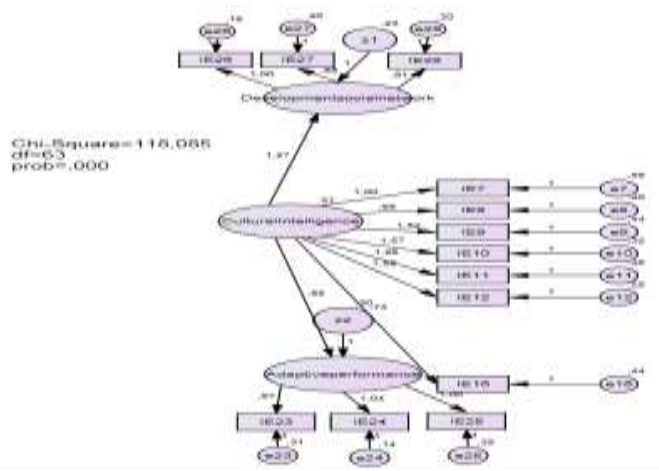

FIGURE 2. Final model after the modification

The degrees of freedom value was $63>0$, which indicated that the model was included in the overidentified criteria

\section{Hypothesis Test}

TABLE 6. Regression weights (Group number 1 - Default model)

\begin{tabular}{|c|c|c|c|c|}
\hline & & & Estimate & $P$ \\
\hline Developmentsocialnetwork & $<---$ & CulturalIntelligence & 1,267 & $* * *$ \\
\hline Adaptiveperformance & $<--$ & CulturalIntelligence & ,947 & $* * *$ \\
\hline IE7 & $<---$ & CulturalIntelligence & 1,000 & \\
\hline IE8 & $<---$ & CulturalIntelligence & ,953 & *** \\
\hline IE9 & $<--$ & CulturalIntelligence & 1,519 & $* * *$ \\
\hline IE10 & $<---$ & CulturalIntelligence & 1,571 & $* * *$ \\
\hline IE11 & $<<--$ & CulturalIntelligence & 1,261 & $* * *$ \\
\hline IE12 & $<---$ & CulturalIntelligence & 1,517 & $* * *$ \\
\hline IE16 & $<---$ & CulturalIntelligence & ,735 & $* * *$ \\
\hline IE26 & $<---$ & Developmentsocialnetwork & 1,000 & \\
\hline IE27 & $\begin{array}{ll}<-- \\
\end{array}$ & Developmentsocialnetwork & ,875 & *** \\
\hline IE28 & $<<--$ & Developmentsocialnetwork & 906 & *** \\
\hline IE25 & $<---$ & Adaptiveperformance & 1,000 & \\
\hline IE24 & $<<--$ & Adaptiveperformance & 1,043 & *** \\
\hline IE23 & $<<--$ & Adaptiveperformance & 970 & $* * *$ \\
\hline
\end{tabular}

The influence or correlation test for the hypothesis 1 and 2 could not be conducted since there were no indicators that could explain the latent variables of Vacation Abroad and Education Abroad. If it is necessary to analyze the correlation, so in this case, Hypothesis 1 and 2 were rejected.

Hypothesis 3 and 4 could be said to be proven, because based on the table above, the correlation between $\mathrm{CI}$ and Adaptive Performance had a p-value of $<0.05\left({ }^{* * *}\right)$ which indicated a value far below 0.05$)$, as well as CI and Social Network Development. It can be concluded that there was a correlation between the CI and Adaptive Performance and there was a correlation between $\mathrm{CI}$ and Social Network Development with the structural form of the model was social network Development $=1.27$ Cultural Intelligence +0.23 and Adaptive Performance $=0.95$ Cultural Intelligence +0.31 . Based on the model it appears that the correlation between $\mathrm{CI}$ and Adaptive Performance and the correlation between $\mathrm{CI}$ and Social Network Development had a positive correlation. 
DISCUSSION

From the research that has been conducted, hypothesis 1 and hypothesis 2 that education abroad and vacation abroad had an impact on CI was not proven. This was presumably due to lack of precise instruments used in this study. Earlier research instrument of vacation abroad and education abroad was initially used for managers as respondents. So when the same instrument was used for student respondents, the context was not necessarily the same.

The respondents were Indonesian students abroad (Malaysia, Thailand, India) who received scholarships and financial aid from the government to study abroad. According to the information from the Indonesian Students Association board of regional Malaysia, the majority of students there were there also work part time to earn more money in order to meet their needs there. Even the traveling to other countries may only be conducted in countries where students were studying in a vacation time. Therefore it can be said that in this study vacation was not one contributing factor that could affect the height of Cultural Intelligence of Indonesian students. Cultural intellige height of Indonesian students in this study was suspected to be affected due to interaction with other cultures when they performed part time work.

According to $\mathrm{Ng}$ et al. (2012) education abroad should have a positive impact on Cultural Intelligence, but in fact it was not proven in this study. The possibility of constraints experienced here is the same with vacation abroad that is the limited funds that do not allow students to study abroad in various countries, and in a long period of time.

Students' Residence and environment also influence the effect of education with Cultural Intelligence. As stated by the Indonesian Students Association board in Thailand (PERMITHA) that students are generally clustered in the residence. From the information obtained from the PPI management of Thailand, on average the students there were placed or seeking shelter in the Indonesian people who were already there before. So it can be presumed that the living environment is not conducive to interact with many cultures.

Since education abroad and vacation abroad were not proven to affect the Cultural Intelligence can also be caused by the questionnaires distributed to the respondents. Questionnaires distributed were drawn from the study conducted by Ang et al. (2011) that was addressed to the workers in developed countries who might not fit the conditions of the students, especially the Indonesian students. For example in the vacation abroad variable which stated that holidays in several countries would increase an individual's Cultural Intelligence. The workers have more funds than the students, even more the respondents here were taken from workers from developed countries. Culture of Holidays will also be different compared to developing countries such as Indonesia. In Indonesia Holidays are not as becoming a necessity that must be met by every individual, especially holidays abroad which require a lot of funds.

At this study, Cultural Intelligence was proved to influence Social Network Development and Adaptive Performance. This is in line with the study conducted by $\mathrm{Ng}$ et al. (2012). By having a high Cultural Intelligence, it is possible to easily search for friends to socialize. Knowledge of foreign languages and awareness of cultural differences affect a person's ability to easily fit into a new environment and get new friends from different tribal customs and culture. If someone does not have a high Cultural Intelligence then it is difficult to get 
new friends in the new environment, even there will be many disputes and disharmony due to frequent misunderstanding about the customs one another.

A person who holds a high Cultural Intelligence will also benefit in terms of adapting to the new environment which can be seen from the performance of the work done. By having a high Cultural Intelligence then one does not hesitate to be placed in a new environment that is not much information about the place, especially the culture and customs that are owned by local people. A student would need to see this, because a prospective employee would normally be placed in the cities and other countries in the future work time. Has a high Intelligence Cultural certainly have a positive impact at work so someone is not awkward to interact with the local community which has different culture and the way of life.

Not only that, high Cultural Intelligence can also affect a person's level of creativity in the work. If a person enters into a new environment, he or she will usually get high stress pressure due to cultural shock, which can affect the performance in completing the task. But someone who has a high Cultural Intelligence will be able to overcome it so he or she will work with more creative and productive without the need to think about cultural shock derived from the surrounding environment.

\section{CONCLUSION}

- This study showed that the Cultural Intelligence had an impact on Development Social Network and Adaptive performance.

- Vacation abroad and education abroad were not proved to affect $\mathrm{CI}$ in this study. However it was found that Indonesian students could increase their CI through mingle with people in other countries, among others through a parttime job in a foreign country.

\section{THEORETICAL IMPLICATIONS}

In this study it was found that there was no impact of International Exposure (Vacation Abroad and Education Abroad) on Cultural Intelligence of Indonesian students. The measurements were equated with the study conducted by $\mathrm{Ng}$ and Christopher (2006) which actually could not be applied to the student respondents. Previous research took a sample of workers from other countries who had better financial condition than Indonesian students as the samples in this study. But the indicator that was taken to measure the impact of Cultural Intelligence and Performance was right. This is consistent with the research conducted by Ng and Christopher (2006) that CQ had an impact on adaptive performance in each individual in adapting to the environment. It is in line with the statements by $\mathrm{Ng}$ et al. (2012) and Ang et al. (2011) that Cultural Intelligence is one person's ability which can affect the number of social relationships outside the geographic boundaries with different cultures and ethnicities.

\section{LIMITATIONS AND RECOMMENDATIONS}

There was an instrument in this study that caused the data could not be processed properly. By replacing it by other instrument according to the study to be conducted is expected to produce better data. Therefore, further research 
can replace the study instrument with more suitable instrument so as to produce different and better study.

In addition, study model retest can also be conducted by adding some variables that may be more influential and have not been used in this study. Or another test method can also be conducted that may increase the accuracy and different understanding of the study.

In this study, there was also a constraint in collecting data from respondents that caused the data to be taken did not have the general characteristics of respondents and we could not see the differences between one respondents group with another group. It could be that viewing respondents with different economic condition may provide different answers compared to this study.

The further studies can search respondents by paying attention to the difference of respondent's characteristics or by comparing answers from one respondent's characteristic with another characteristic. The characteristics to be taken are for example economic and geographic aspects difference and behaviour difference of each individual as a respondent. Thus, the further studies are expected to provide better results by taking more complex data.

\section{REFERENCES}

Ang, Soon, Linn Van Dyne, and Christine Koh. 2005. Personality correlates of the four factor model of cultural intelligence. Group and Organization Management 31, no. 1, 100-123. DOI: doi.org/10.1177/1059601105275267

Ang, Soon, Linn Van Dyne, and Thomas Rockstuhl. 2011. Cultural intelligence. In Cambridge handbook on intelligence: 582-602, eds. Robert J. Sternberg, and Scott Barry K. New York, NY: Cambridge Press. D0I: $10.1017 /$ cbo9780511977244.030

Crowne, Kerri A. 2008. What leads to cultural intelligence? Business Horizon 51, no. 5: 391-399. D0I: 10.1016/j.bushor.2008.03.010

De Lange, Daniëlle, Filip Agneessens, and Hans Waege. 2004. Asking social network questions: A quality assessment of different measures. Metodološki zvezki 1, no. 2: 351-378.

Earley, P. Christopher, and Soon Ang. 2003. Cultural intelligence: An analysis of individual interactions across cultures. Palo Alto, CA: Stanford University Press.

Fernandes, J.A.P.S.E., and dan Andadari, R.K. 2012. Persepsi mahasiswa terhadap pemberlakuan masyarakat ekonomi ASEAN. FEB UKSW program studi S1 Manajemen, Salatiga, ID.

Friedman, Thomas L. 2005. The world is flat: a brief history of the twenty-first century. New York, NY: Farrar, Straus and Giroux.

Hair, Joseph F., and Black William C. 2000. Cluster analysis. In Reading and understanding more multivariate statistics, eds. Laurence G. Grimm, and Paul R. Yarnold, Washington DC, US: American Psychological Association.

Harrison, J. Kline, and Brower, Holly H. 2011. The impact of cultural intelligence and psychological hardiness on homesickness among study abroad students. The Interdisciplinary Journal of Study Abroad 21: 41-62.

Kanten, Pelin. 2014. The effect of cultural intelligence on career competencies and customer-oriented service behaviors. Istanbul University Journal of the School of Business 43, no. 1: 100-119.

Kitsantas, Anastasia, and Meyers, Judith. 2001. Studying abroad: Does it enhance college student cross-cultural awareness? Paper presented at the combined Annual Meeting of the San Diego State University and the U.S. Department of Education Centers for International Business Education and Research, US.

Leung, Kwok, Soon Ang and Mei Ling T. 2014. Intercultral competence. Annual Review of Organizational Psychology and Organizational Behavior 1: 489-519. D0I: 10.1146/annurev-orgpsych-031413-091229

Livermore, David. 2009. Leading with cultural intelligence. New York, NY: AMACOM.

Ng, Kok-Yee, Linn Van Dyne, and Soon Ang. 2012. Cultural intelligence: A review, reflections, and recommendations for future research. In Conducting multinational research: Applying organizational psychology in the workplace, 
eds. Ann Marie R, Frederick T.L. Leong, and Frederick L. Oswald: 29-58. Washington, DC, US: American Psychological Association. DOI: 10.1037/13743-002

Ng, Kok-Yee, and P. Christopher Earley. 2006. Culture+ intelligence old constructs, new frontiers. Group \& Organization Management 31, no. 1: 4-19. DOI: 10.1177/1059601105275251

Pangestu, Mari E. 2009. Competitiveness toward ASEAN economic community. Journal of Indonesian Economy and Business 24, no. 1: 22-32.

Rockstuhl, Thomas, Stefan Seiler, Soon Ang, Linn Van D., and Hubert Annen. 2011. Beyond general intelligence (IQ) and emotional intelligence (EQ): The role of cultural intelligence (CQ) on cross-border leadership effectiveness in a globalized world. Journal of Social Issues 67, no. 4: 825-840. DOI: 10.1111/j.1540-4560.2011.01730.x

Rose, Raduan C., and Naresh Kumar S. 2008. A review on individual differences and cultural intelligence. The Journal of International Social Research 1, no. 4: 504-522.

Shieh, Chich-Jen. 2013. Effects of culture shock and cross-cultural adaptation on learning satisfaction of mainland China students studying in Taiwan. Revista Internacional de Sociología 72, no. 2: 57-67.

Shoss, Mindy K., L. A. Witt, and Dusya Vera. 2012. When does adaptive performance lead to higher task performance?. Journal of Organizational Behavior 33, no. 7: 910-924. DOI: 10.1002/job.780

Soldatova, Galina, and Marina Geer .2013. "Glocal” identity, cultural intelligence, and language fluency. Procedia-Social and Behavioral Sciences 86: 469-474. D0I: 10.1016/j.sbspro.2013.08.599

Takeuchi, Riki, Paul E. Tesluk, Seokhwa Yun, and David P. Lepak. 2005. An integrative view of international experience. Academy of Management Journal 48, no. 1: 85-100. D0I: 10.5465/AMJ.2005.15993143

UNDP. (2013). Human development report. UNDP. URL: http://goo.gl/XDqAs4 (accessed June 16, 2016). D0I: $10.18356 / \mathrm{a} 1 \mathrm{~b} 0 \mathrm{c} 169$-en

- This article does not have any appendix. - 